\title{
Noni fruit's water spot appearance on the second day of harvest: a trade-off between resistance and energy
}

\author{
Tian Wu ${ }^{*}$, Danyan Hu and Qingfen Wang
}

\begin{abstract}
Background: Noni (Morinda citrifolia Linn.) is a tropical tree that bears climacteric fruit. Previous observations and research have shown that the second day ( $2 \mathrm{~d})$ after harvest is the most important demarcation point when the fruit has the same appearance as the freshly picked fruit $(0 \mathrm{~d})$; however, they are beginning to become water spot appearance. We performed a conjoint analysis of metabolome and transcriptome data for noni fruit of $0 \mathrm{~d}$ and $2 \mathrm{~d}$ to reveal what happened to the fruit at the molecular level. Genes and metabolites were annotated to KEGG pathways and the co-annotated KEGG pathways were used as a statistical analysis.

Results: We found 25 pathways that were significantly altered at both metabolic and transcriptional levels, including a total of 285 differentially expressed genes (DEGs) and 11 differential metabolites through an integrative analysis of transcriptomics and metabolomics. The energy metabolism and pathways originating from phenylalanine were disturbed the most. The upregulated resistance metabolites and genes implied the increase of resistance and energy consumption in the postharvest noni fruit. Most genes involved in glycolysis were downregulated, further limiting the available energy. This lack of energy led noni fruit to water spot appearance, a prelude to softening. The metabolites and genes related to the resistance and energy interacted and restricted each other to keep noni fruit seemingly hard within two days after harvest, but actually the softening was already unstoppable.
\end{abstract}

Conclusions: This study provides a new insight into the relationship between the metabolites and genes of noni fruit, as well as a foundation for further clarification of the post-ripening mechanism in noni fruit.

Keywords: Metabolomics, Transcriptomics, Metabolite, Differentially expressed gene, LC-MS, Morinda citrifolia linn

\section{Background}

Morinda citrifolia Linn., known as noni as well, is a perennial shrub or tree widely distributed in tropical and subtropical regions [1]. It originated from the Southern Pacific Ocean, such as Polynesian, Marquesas, and Hawaiian, and has been used traditionally in folk medicine for more than 2000 years [2]. During the past centuries, cultivation of noni has stretched to the other

\footnotetext{
*Correspondence: wutianpotato@swfu.edu.cn

Key Laboratory for Forest Resources Conservation and Utilization

in the Southwest Mountains of China, Ministry of Education, Southwest Landscape Architecture Engineering Research Center of State Forestry

Administration, Southwest Forestry University, Kunming 650224, Yunnan, China
}

tropical regions, including Caribbean, South America, and Southeast Asia [3]. Noni is rich in numerous biological compounds, such as glycosides, alkaloids, polysaccharides, fatty acids, and lignans, as well as various minerals, including selenium, sulfur, phosphorus, calcium, and potassium [4,5]. Noni juice is approved as one of the whole foods by the European Union's 1997 novel food regulations, and also as a safe new resource and functional food improving human immunity by the Chinese government. Noni juice has since become a commercially marketed health drink in more than 80 nations [6].

Noni is popular worldwide due to its perceived health value. Numerous kinds of health benefits have been reported, including increased energy, improved 
digestion, reduction in allergy and asthma symptoms, lower pain, fewer infections, and better sleep [7]. More and more studies have provided information on phytochemical compositions of noni fruit, finding variations according to regions, picking time, storage life, and processing methods [8]. Noni fruit is climacteric and easily ripens after harvest, which is not conducive to long-term storage and long-distance transportation and marketing, limiting its wider promotion to some extent. As a result, it is of great significance to study the softening mechanism of noni fruit after harvest.

Noni fruit is fleshy, greenish-white to yellowish-white and hard in its initial stage of maturity. At full maturity, the fruit becomes gray-white and soft, when the fruit is at an advanced stage of ripening, it has a unique odor (some people think it is unpleasant, but others find it acceptable) [9]. A single noni fruit can contain up to 260 seeds [10], which can form a framework which prevents the fruit from collapsing quickly, even if it softens. Softening as an indication of ripening is, therefore, often disregarded. Before noni fruit becomes gray-white, water spot appearance around the inlaid seeds appears on the fruit surface at the beginning of the initiation of softening. Some reported mechanisms of softening in postharvest fruit involve cell wall metabolism, starch metabolism, energy metabolism, hormone regulation, and pathogen infection [11-13]. The biggest challenge of postharvest fruit is the proliferation of fungi and bacteria, because of their ability to grow under storage conditions, thereby, damaging fruit directly [14]. When attacked by pathogens or fungi, postharvest fruit can activate their defense systems to improve their resistance [15]. By activating resistance mechanisms, plants prioritize the use of energy for their survival against a threat, which drives changes in the allocation of energy resources within the fruit.

Although some research progress has been made on the softening mechanism in some fruits [12-14], there are very few reports on how the fruit enters the softening stage, or the molecular mechanism regulating fruit softening in harvested noni. In a previous study, Wu et al., using liquid chromatography-mass spectrometry (LC-MS), showed that the metabolites within noni fruit vary at different ripening stages $(0,2,4$, and 6 days after harvest) when the fruit is in postharvest storage [16]. The 2nd day has been identified as the key point when noni fruit appears similar to that of 0 -day fruit, but in the subsequent day, it quickly softens and smells. Furthermore, RNA-seq was performed using 0- and 2-day postharvest noni fruit, and conducted verification of the qRT-PCR. The results formed the bases for the present research.

\section{Materials and methods Plant material}

The noni plants were grown on a farm in Yuanjiang, Yunnan province, China, with an average elevation of approximately $350 \mathrm{~m}$, average temperature of $25^{\circ} \mathrm{C}$, and an average annual precipitation of $560 \mathrm{~mm}$. When the noni fruit is greenish-white in color, slightly hard, and has a relatively smooth surface, it has reached maturity and is at optimal harvesting time (Fig. 1a). When the fruit is cut in half vertically, the flesh is fresh and white (Fig. 1b). This is the 0-day $(0 \mathrm{~d})$ sample used in the experiment. After 2 days $\left(48 \mathrm{~h}\right.$ ) of storage under $25^{\circ} \mathrm{C}$ and $50-70 \%$ humidity, the color and the hardness of noni fruit seem similar with that of $0 \mathrm{~d}$ fruit, but on close observation, some water spot appearance can be found near the seed insertion on the surface (Fig. 1c). Cut vertically, the fruit shows a slightly blackened flesh, which is somewhat water spot appearance (Fig. 1d). This is the 2nd day (2 d) sample. After this point, the water spot increases rapidly and the fruit begins to smell until the whole fruit is soft (Figs. 1E, 1F), and it is difficult to extract high-quality RNA. The second day is the critical point of noni fruit softening, and the samples of $2 \mathrm{~d}$ vs. $0 \mathrm{~d}$ were, therefore, used for the conjoint transcriptome and metabolome analysis.

A biological replicate consisted of five randomly selected healthy noni plants, and three to five fruit were collected from each plant. Three biological replicates were conducted for each sample. The freshly picked fruit was sliced, quick-frozen with liquid nitrogen, and stored at $-80{ }^{\circ} \mathrm{C}$. Every replicate was divided into two sections, one was used for metabolomics analysis, while the other was used to extract RNA for RNA-seq.

\section{Data resource}

The RNA was extracted by TRIzol ${ }^{\circledR}$ Reagent (Invitrogen), and mRNA was separated using Magnetic Separation Rack (Invitrogen). The platform was the Illumina Hiseq 2000. The sequencing method was Single end (SE), and the average fragments obtained were $1032 \mathrm{bp}$. The transcriptome dataset was submitted to the database of National Center for Biotechnology Information (NCBI), with an accession number of PRJNA503490. A total of three noni fruit replicates at 0 days $(0 \mathrm{~d})$ and three noni fruit replicates at 2 nd day after harvest $(2 \mathrm{~d})$ were included in PRJNA503490. In transcriptomics analysis, the software were SeqPrep (https://github.com/jstjohn/ SeqPrep) and Sickle (https://github.com/najoshi/sickl e) for quality control of sequencing data, Trinity (http:// trinityrnaseq.sourceforge.net/, version number: trinityrnaseq-r2013-02-25) for sequence assembly and ORF prediction, and RSEM (http://deweylab.biostat.wisc. $\mathrm{edu} / \mathrm{rsem} /$ ) for gene expression analysis. The metabolite 

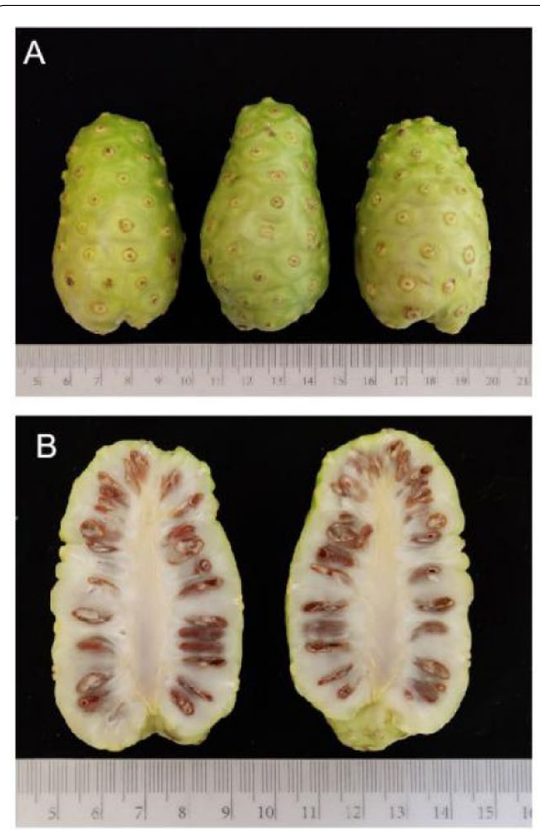

noni fruit at $0 \mathrm{~d}$
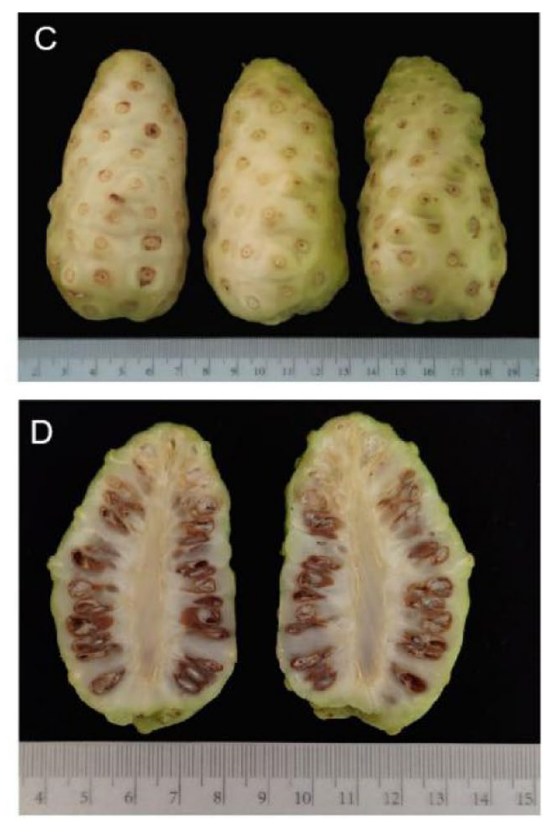

noni fruit at $2 \mathrm{~d}$
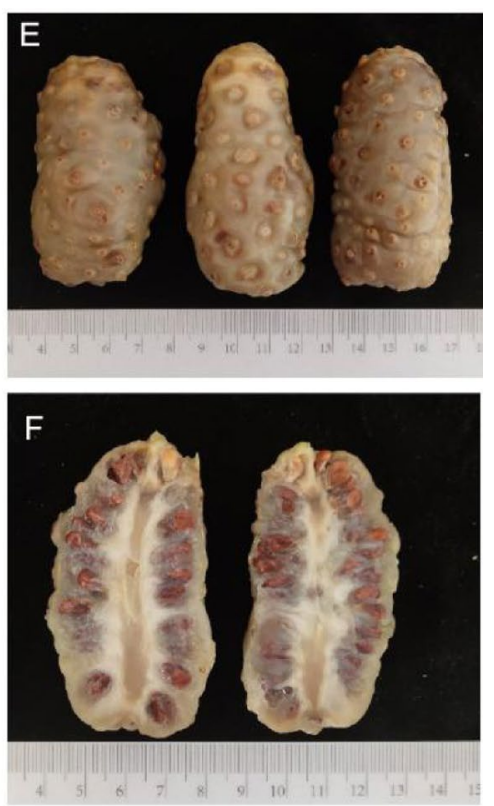

noni fruit soften completely

Fig. 1 Noni fruit at 0 day and 2 day after harvest and the appearance of soften completely. A, C, E: the appearance of complete fruit; B, D, F: the appearance of cutting noni fruit in half. The smallest scale on a ruler represents $1 \mathrm{~mm}$

profilings of $0 \mathrm{~d}$ and $2 \mathrm{~d}$ fruit using the liquid chromatography-mass spectrometry (LC-MS) method were detailed and the metabolome dataset was obtained from the study of Wu et al. [16].

\section{Correlation analysis between transcriptome and metabolome}

To understand the relationship between genes and metabolites in the noni fruit of $2 \mathrm{~d}$ relative to $0 \mathrm{~d}$, a correlation analysis was carried out for gene expression levels and metabolites using Spearman's Rank Correlation Coefficient in SPSS 24.0 (SPSS Inc., USA). The genes and metabolites were selected when the correlation was $\geq 0.9$ or $\leq-0.9$. The correlation analysis was performed between DEGs (differentially expressed genes) in the transcriptome and differential metabolites in the metabolome. The genes and metabolites were annotated to KEGG (Kyoto Encyclopedia of Genes and Genomes) pathways and the co-annotated KEGG pathways were used as a statistical analysis. The same statistical analysis was conducted on significantly different genes and metabolites.

\section{Results and discussion}

25 pathways were significantly varied at both metabolic and transcriptional levels

There were 25 pathways significantly varied at both metabolic and transcriptional levels (Additional file 1: Table S1), including a total of 285 DEGs and 11 differential metabolites. To better understand these pathways, they were classified into primary and secondary metabolic pathways. Among them, the primary metabolic pathways included three pathways related to carbohydrate and energy metabolism and seven amino acid-related pathways. Secondary metabolic pathways included three pathways originating from phenylalanine, three terpene-related pathways, and a glycerolipid metabolism pathway. As for other pathways, they only contained a few downregulated genes or the FPKM (Fragments Per Kilobase Million) had a value of 0 or close to 0 in one biological replicate, and no or very few metabolites with significant differences were detected; therefore, these other pathways were not analyzed in the following correlation analysis.

\section{Disordered energy metabolism, enrichment of DEGs in galactose metabolism, and downregulation of D-Tagatose}

There are three pathways related to carbohydrate and energy metabolism: carbon fixation in photosynthetic organisms, carbon metabolism, and galactose metabolism. Among these pathways, galactose metabolism enriched the most differential genes. The thirteen DEGs showed significantly upregulated and nine DEGs showed significantly downregulated (Table 1).

Central carbon metabolism, consisting of glycolysis, pentose phosphate pathway (PPP), and the tricarboxylic 
Table 1 DEGs related to carbohydrate and energy metabolism

\begin{tabular}{|c|c|c|c|c|c|c|c|c|}
\hline No. & $0 d-1$ & $0 d-2$ & $0 d-3$ & $2 d-1$ & $2 d-2$ & $2 d-3$ & FC & Description \\
\hline \multicolumn{9}{|c|}{ Upregulation } \\
\hline 1 & 16.62 & 10.84 & 6.61 & 39.63 & 57.26 & 44 & 4.14 & Malate dehydrogenase (MDH) \\
\hline 2 & 8.20 & 5.10 & 1.75 & 12.46 & 19.07 & 14.38 & 3.05 & Glucose-6-phosphate 1-dehydrogenase (G6PDH) \\
\hline 3 & 484.03 & 719.87 & 229.71 & 1851.71 & 1866.07 & 1915.37 & 3.93 & Galactinol-sucrose galactosyltransferase (RFS) \\
\hline 4 & 13.18 & 37.97 & 21.13 & 69.05 & 76.78 & 104.96 & 3.47 & RFS \\
\hline 5 & 1.15 & 7.35 & 3.04 & 12.87 & 17.42 & 29.74 & 5.20 & RFS \\
\hline 6 & 0.75 & 0.55 & 0.64 & 3.86 & 4.22 & 13.64 & 11.20 & RFS \\
\hline 7 & 1.12 & 5.27 & 0.64 & 7.08 & 9.50 & 12.24 & 4.10 & RFS \\
\hline 8 & 269.44 & 223.8 & 146.64 & 866.23 & 843.78 & 865.44 & 4.02 & $\begin{array}{l}\text { Bifunctional UDP-glucose 4-epimerase and UDP-xylose 4-epimer- } \\
\text { ase (bifunctional UGE and UXE) }\end{array}$ \\
\hline 9 & 28.43 & 28.4 & 13.94 & 110.39 & 103.51 & 121.67 & 4.74 & Bifunctional UGE and UXE \\
\hline 10 & 102.64 & 130.93 & 119.09 & 374.53 & 357.95 & 413.35 & 3.25 & NADP-dependent D-sorbitol-6-phosphate dehydrogenase (S6PDH) \\
\hline 11 & 7.22 & 7.89 & 6.91 & 27.84 & 29.13 & 27.93 & 3.86 & hexokinase $(\mathrm{HXK})$ \\
\hline 12 & 3.87 & 4.17 & 1.25 & 9.21 & 14.17 & 16.50 & 4.29 & Aldo-keto reductase (AKR) \\
\hline 13 & 4.66 & 3.8 & 1.13 & 23.79 & 28.67 & 25.83 & 8.16 & Alpha-galactosidase (a-GAL) \\
\hline \multicolumn{9}{|c|}{ Downregulation } \\
\hline 1 & 54.01 & 36.52 & 34.5 & 5.93 & 10.31 & 6.23 & 5.56 & Phosphoglycerate kinase (PGK) \\
\hline 2 & 1.31 & 1.66 & 44.37 & 1.29 & 4.41 & 1.68 & 6.41 & Pyruvate phosphate dikinase (PPDK) \\
\hline 3 & 116.96 & 107.3 & 91.06 & 9.29 & 16.75 & 13.47 & 7.98 & Chloroplastic pyruvate kinase (PKC) \\
\hline 4 & 12.14 & 13.9 & 6.78 & 2.22 & 1.59 & 1.10 & 6.68 & Plastid pyruvate kinase (PKP) \\
\hline 5 & 7.32 & 16.98 & 11.96 & 1.11 & 1.02 & 1.82 & 9.18 & Bifunctional L-3-cyanoalanine synthase/cysteine synthase (CYSC) \\
\hline 6 & 52.02 & 38.71 & 31.57 & 6.04 & 9.23 & 8.13 & 5.23 & Neutral alpha-glucosidase C \\
\hline 7 & 13.79 & 9.05 & 7.33 & 1.35 & 2.39 & 1.17 & 6.14 & Beta-galactosidase ( $\beta-G A L)$ \\
\hline 8 & 5.91 & 8.07 & 9.08 & 1.40 & 2.45 & 1.24 & 4.53 & Hexokinase (HXK) \\
\hline 9 & 2.48 & 1.83 & 82.87 & 1.01 & 2.41 & 2.1 & 15.79 & Galactinol synthase (GOLS) \\
\hline
\end{tabular}

$0 \mathrm{~d}$ and $2 \mathrm{~d}$ means fresh-picked noni fruit and the fruit of start-to-soften (store at room temperature for 2 day), respectively. And the numbers 1,2 , and 3 mean the number of replicates. The same as Table 2

acid cycle (TCA), functions in the energy and cofactor regeneration as well as biosynthetic precursor supply in higher plants [17]. The DEGs in Table 1 could be targeted in the associated pathways to better understand energy metabolism. Glycolysis provides energy in the form of ATP and reducing power [18]. The genes of PGK (phosphoglycerate kinase), PPDK (pyruvate phosphate dikinase), PKC (chloroplastic pyruvate kinase), PKP (plastid pyruvate kinase), and HXK (hexokinase) were all involved in glycolysis and were all downregulated except for one copy of $H X K$. PGK, a major enzyme in glycolysis and the first ATP-generating step of this pathway, was downregulated by 5.56 -fold (Table 1 ). PGK can participate in photosynthetic and glycolytic/gluconeogenic reactions at the same compartment and/or at the same time, so the function of it is of crucial importance [19]. Pyruvate kinase (PK) is responsible for catalyzing in the last step of glycolysis, including both cytosolic (PKC) and plastid (PKP) isozymes [18]. PKP is vital for providing pyruvate and ATP to multiple plastidic biosynthetic pathways, whereas PKC functions more complicatedly because it acts in a range of biosynthetic pathways and respiration [20], such as resistance to disease [21] and fruit ripening [22]. PPDK catalyzes pyruvate to phosphoenolpyruvate (PEP), consuming ATP to produce AMP in the process. HXKs can regulate glycolysis and supply substrates to several pathways and also act as glucose sensors regulating the gene expression of central cellular components and secondary metabolism [23]. In summary, the universal downregulation of these genes in glycolysis by more than fivefold on the 2nd day after harvesting of noni fruit is speculated to cause a weakening of glycolysis, which would lead to a decrease in energy availability, and then directly lead to postharvest senescence of the fruit.

In addition, one gene in TAC and one gene in PPP were significantly upregulated. MDH (malate dehydrogenase) is a key enzyme of TAC, catalyzing oxaloacetate to produce malic acid with $\mathrm{NAD}^{+}$[24]. $M D H$ was upregulated by 4.14 -fold in the $2 \mathrm{~d}$ sample relative to the $0 \mathrm{~d}$ sample (Table 1). G6PDH (glucose-6-phosphate 1-dehydrogenase) was upregulated by 3.05 -fold (Table 1 ) and is a key enzyme limiting the PPP by reducing $\mathrm{NAD}^{+}$to NADH [25]. Thus, TAC and PPP were also affected on the 2nd 
day after harvest in noni fruit, which leads to changes in the energy state via the consumption of $\mathrm{NAD}^{+}$.

In galactose metabolism, there were the DEGs associated with sugar metabolism, including genes encoding RFS (galactinol-sucrose galactosyltransferase) (five DEGs) and bifunctional UGE (UDP-glucose 4-epimerase) and UXE (UDP-xylose 4-epimerase) (two DEGs), S6PDH (NADP-dependent D-sorbitol-6-phosphate dehydrogenase), and Gal (galactosidase). The five RFS genes were all upregulated by $3.37--11.20$-fold in the $2 \mathrm{~d}$ fruit relative to the $0 \mathrm{~d}$ fruit (Table 1). RFS is the key enzyme catalyzing sucrose and galactinol into raffinose and is the second step of the biosynthesis of RFOs (raffinose family of oligosaccharides) [26]. Raffinose is a widespread oligosaccharide in plants and participates in the transport and storage of carbon [27]. In addition, raffinose and its precursor galactinol accumulate in plants under various abiotic stresses, so RFS could be regarded as a protector regulating gene expression by controlling reactive oxygen species (ROS) levels [28]. S6PDH, namely aldose 6-phosphate reductase, is a vital enzyme in sorbitol biosynthesis [29]. Its expression is closely related to photosynthesis, source-sink intensity and distribution of photosynthetic products, and has an obvious relationship with the plant's resistance to abiotic and biotic stresses [30]. The consistent upregulation of RFS and $S 6 P D H$ genes in noni fruit are likely to increase the defense resistance and oxidation resistance of the fruit after harvesting, which consumes energy.

In response to the postharvest noni fruit, besides $R F S$ and $S 6 P D H$, other resistance-related genes were found that involved the upregulated genes of G6PDH and $A K R$ (aldo-keto reductase) as well as the downregulated genes of CYSC (bifunctional L-3-cyanoalanine synthase/cysteine synthase) and GolS (galactinol synthase). G6PDH is reported in response to abiotic stresses and pathogenesis and reduces the level of ROS in plants [31]. AKRs are a superfamily of enzymes participating in redox reactions, and due to their lack of substrate specificity, the genes may be involved in widespread toxicant metabolism [32]. It was reported that a deficit in tissue energy was a key factor in the aging of postharvest fruits [33]. The upregulation of these genes is beneficial for the response to biotic and abiotic stress after harvest in noni, but the upregulation of resistance genes is an energyconsuming process, and the continuous upregulation of resistance genes may lead to energy dissipation in postharvest tissues at the later stage of storage.

CYSC, a kind of cyanoalanine synthase, could degrade the toxicity of cyanide and scavenge ROS in plants [34]. Gols genes are good targets for improving the abiotic stress tolerance of higher plants [35]. The downregulated expressions of these two genes is unfavorable for detoxification and response to stress in noni fruit after harvest, but it may save energy to some extent. In a word, from the expression characteristics of these resistance genes, the genes in postharvest noni fruit might not only relate to biotic and abiotic stress but also might be involved in energy consumption, which constitutes a trade-off between the resistance response and energy deficit in the harvested noni fruit.

$\alpha$-Gal was upregulated by 8.16 -fold, while $\beta$-Gal was downregulated by 6.14 -fold in the $2 \mathrm{~d}$ samples relative to the $0 \mathrm{~d}$ samples (Table 1 ). $\alpha$-Gal is rich in many fruits during early softening stages [36], degrading cell galactose, changing the interaction between pectin and other polymers, decreasing cell wall integrity, and producing galactose [37]. It also functions in other responses, including ethylene release and stress responses [38]. $\beta$-Gal affects fruit softening by expanding and softening cell walls [39]. It is speculated that although the downregulation of $\beta$ Gal hinders the softening of noni fruit to some extent, the upregulation of $\alpha$-Gal makes the softening inevitable, and $\alpha$-Gal may also start the ethylene pathway and resistance reaction with the consumption of energy.

D-Tagatose, a peculiar hexokinase, a natural isomer of D-galactose, and the product of galactose metabolism [40], was downregulated by 2.44-fold (Additional file 1 : Table S2). In the biosynthesis pathway of D-tagatose, galactose is a raw material, catalyzed by galactitol dehydrogenase $(\mathrm{GDH})$, and requires $\mathrm{NAD}^{+}$as a co-factor [41]. GolS could catalyze UDP galactose to synthesize galactinol, and RFS could consume galactinol [42]. The downregulation of GolS gene by 15.79-fold (Table 1), as mentioned above, could result in the decrease of galactinol. Moreover, all five RFS genes were significantly upregulated, indicating the consumption of galactinol, which led to a further decrease of galactinol (Fig. 2). Not only was galactinol decreased, but the $G D H$ gene that could synthesize D-Tagatose was not detected in the 2 $\mathrm{d}$ samples relative to the $0 \mathrm{~d}$ samples, which eventually led to the downregulation of D-tagatose. $\mathrm{NAD}^{+}$also decreased after harvest of noni fruit; thus, the lack of $\mathrm{NAD}^{+}$may be an important reason for the downregulation of D-tagatose. In addition, D-tagatose is antibacterial [43], so its reduction could reduce the resistance to pathogens, leading to the softening of noni fruit. To summarize, the downregulation of GolS, the upregulation of five RFSs, and a decrease in $\mathrm{NAD}^{+}$collectively caused the downregulation of $\mathrm{D}$-tagatose. These changes in the noni fruit could reduce resistance reactions and result in fruit softening; however, on the other hand, it may also be a way to save energy after harvest in noni fruit. 


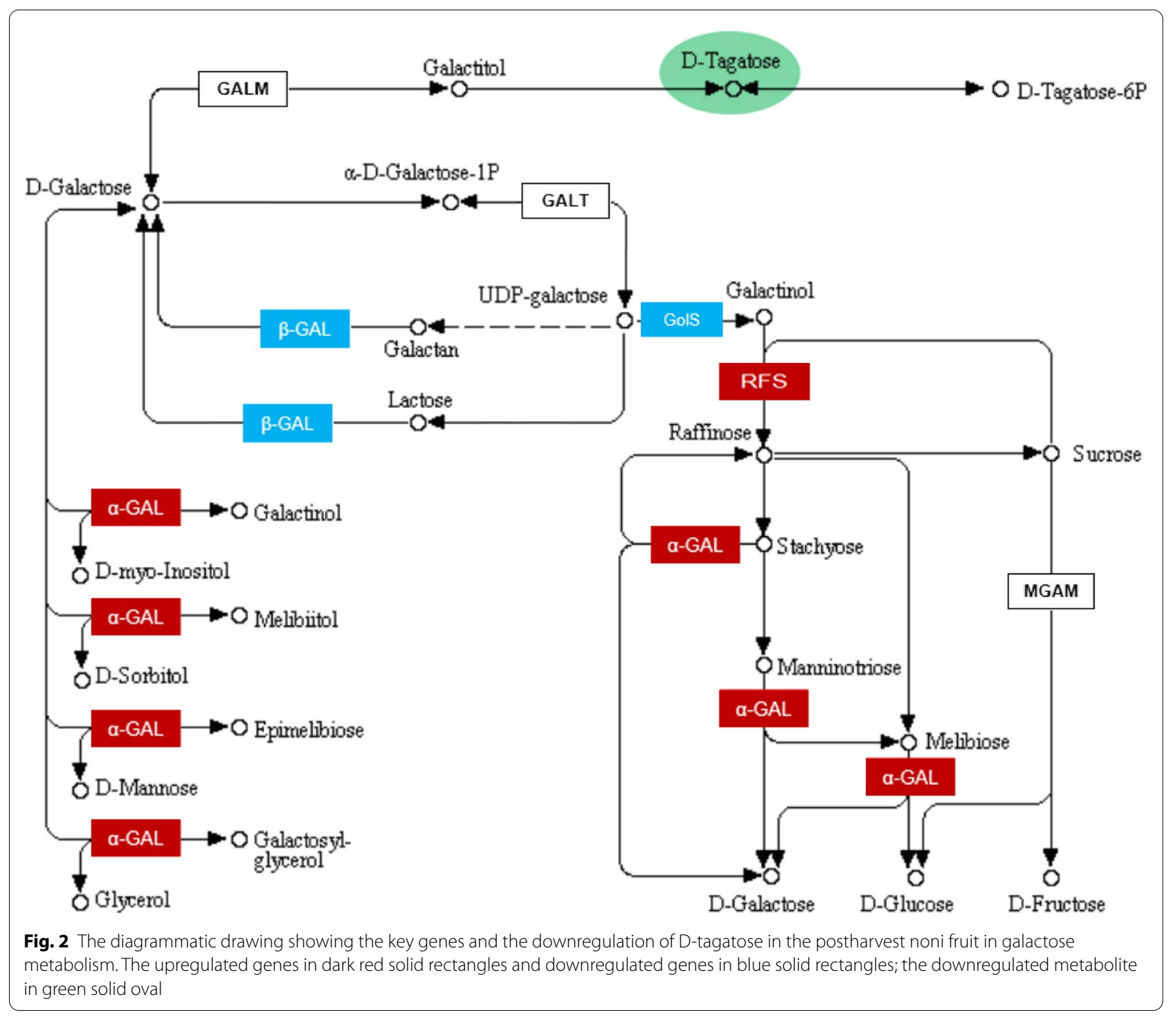

Seven amino acid-related pathways, with the upregulation of Alanine and downregulation of Leucine and 2-oxobutanoate

Seven amino acid-related pathways changed in the noni fruit from the 0 to 2 nd day after harvesting (Additional file 1: Table S1). The genes involved in these pathways underwent complex changes, including ten upregulated genes, such as homocysteine S-methyltransferase (HMT), and twelve downregulated genes (Additional file 1: Table S3). During senescence, amino acids metabolism can counteract the reduction in electron supply from the TCA cycle [44]. The decrease of amino acids during ripening after harvest is usually related to the pathways releasing aroma volatiles and ethylene [45].
Amino acids may also be acted in fruit responses to different stresses and physiological disorders [46]. Numerous amino acid pathways were altered to answer the noni fruit of the second day, and likely impacted energy metabolism, secondary pathways, resistance response, and even ethylene production in harvested noni fruit.

Alanine (Ala) was upregulated by 5.59 -fold in the 2 ndday noni fruit (Additional file 1: Table S2). Ala existed in alanine, aspartate and glutamate metabolism, cysteine and methionine metabolism, biosynthesis of amino acids, as well as protein digestion and absorption. Production of Ala is a vital adaptive process because Ala acts as an osmoprotectant under stress conditions and balances a quick decline in carbohydrates; moreover, the accumulation of Ala seems to be a response to hypoxia in higher 
plants [47]. Therefore, Ala is one of the amino acids that play a key role in noni fruit tolerance to abiotic stresses during postharvest senescence. The upregulation of Ala is speculated to mainly affect energy metabolism and resistance reaction in the postharvested noni fruit.

L-Leucine (Leu) participating in valine, leucine, and isoleucine degradation, biosynthesis of amino acids as well as protein digestion and absorption to reply to the postharvest noni fruit was downregulated by 15.81fold (Additional file 1: Table S2). Leu often decreases in many fruits, such as apples, bananas, strawberries, and tomatoes, to release volatiles, which is the property of branched-chain amino acids like Leu [48-50]. Volatiles often play vital roles in plants defense performance determination [51]. Thus, the decline of Leu indicates the improvement of the resistance response after harvest in noni fruit, which usually takes energy.

2-Oxobutanoate was downregulated in the $2 \mathrm{~d}$ samples relative to the $0 \mathrm{~d}$ samples (Additional file 1: Table S2). In glycine, serine and threonine metabolism, there are two threonine synthase genes: the one upregulated by 26.68 -fold, and the other by 7.83 -fold (Additional file 1: Table S3), suggesting threonine should accumulate within the fruit. Threonine can be catabolized to 2-oxobutanoate by threonine ammonialyase [52]. Because of the downregulation of 2-oxobutanoate and there was no significant difference in threonine ammonia-lyase gene expression in the $2 \mathrm{~d}$ samples relative to the $0 \mathrm{~d}$ samples, it was speculated that the gene did not function. In cysteine and methionine metabolism, homocysteine S-methyltransferase (HMT) can catalyze the conversion of L-homocysteine (Hcy) to L-methionine [53]. In the $2 \mathrm{~d}$ samples relative to the $0 \mathrm{~d}$ samples, three genes were encoding HMT with an upregulation of 13.69-fold, 18.37-fold, and 12.77-fold (Additional file 1: Table S3), indicating that a large amount of methionine could be accumulated. However, methionine was not found in the metabolome in the 2nd-day noni fruit, indicating that it was further metabolized. Methionine can be catalyzed into S-adenosyl-L-methionine (SAM), which is the vital methyl donor in cells and used for the biosynthesis of 2-oxobutanoate and ethylene [54]. 2-Oxobutanoate and S-adenosylhomocysteinase (SAHase) gene were both downregulated, so the branch might direct toward ethylene synthesis (Fig. 3). Ethylene can trigger ripening, particularly in climacteric fruits [55]. However, ethylene was not detected in our results, which could be due to the use of LC-MS rather than GC-MC (Gas chromatography-mass spectrometry), or because the related intermediate metabolites of ethylene were not detected. Intermediate metabolites of ethylene may not have been detected because large-scale synthesis of ethylene had not yet occurred on the second day after noni harvest, which is consistent with the noni fruit looking similar on day 2 vs. day 0 , with no significant softening. In short, based on our result of transcriptome and metabolomics, 2-oxobutanoate was downregulated not only because the threonine ammonia-lyase gene did not work but also because the synthesis route was biased to the ethylene pathway to have provoked ripening.

\section{In pathways originating from Phe, $\beta$-glu gene is the most important, with upregulation of coumarin and vanillin} Three pathways originated from phenylalanine (Phe): phenylpropanoid biosynthesis, phenylalanine metabolism, and flavonoid biosynthesis. Phenylpropanoid biosynthesis was disturbed the most. Table 2 lists the DEGs

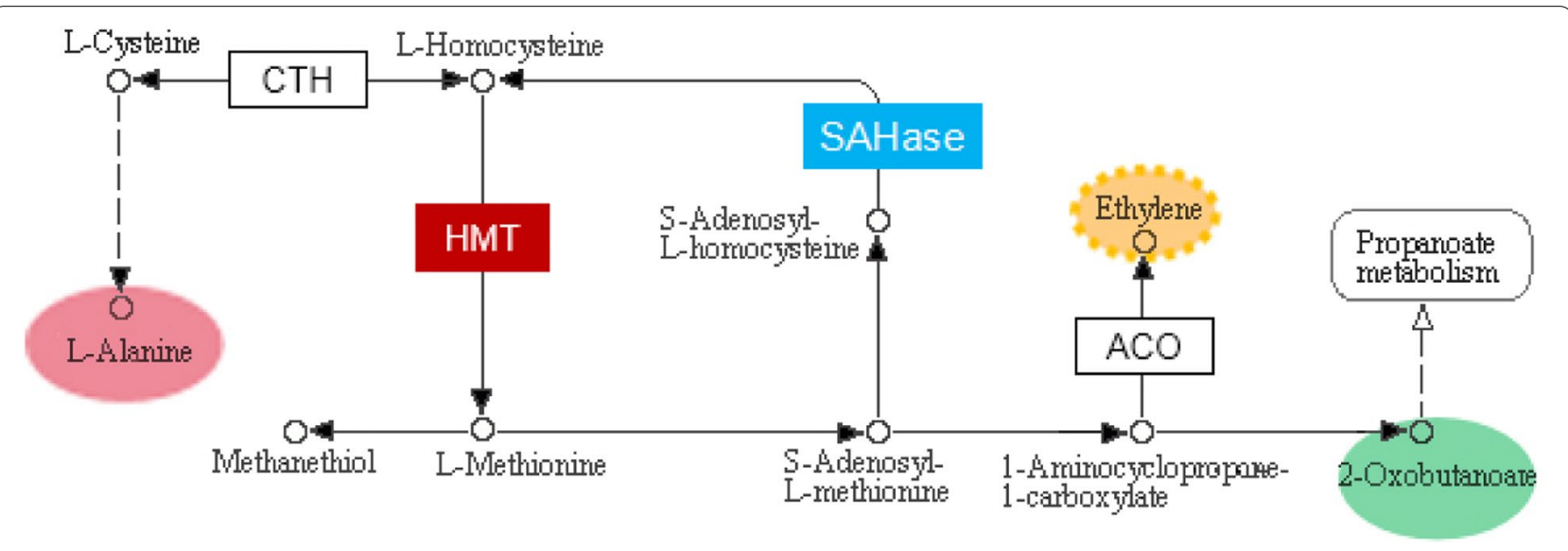

Fig. 3 The diagrammatic drawing of 2-oxobutanoate and ethylene in cysteine and methionine metabolism. The upregulated gene in dark red solid rectangles and downregulated gene in blue solid rectangles; the upregulated metabolites in pink solid oval and downregulated metabolite in green solid oval. Ethylene was marked in yellow 
Table 2 DEGs in pathways originating from phenylalanine

\begin{tabular}{|c|c|c|c|c|c|c|c|c|}
\hline No. & $0 d-1$ & $0 d-2$ & $0 d-3$ & $2 d-1$ & $2 d-2$ & $2 d-3$ & $\mathrm{FC}$ & Description \\
\hline \multicolumn{9}{|c|}{ Upregulation } \\
\hline 1 & 52.01 & 9.92 & 4.65 & $21,279.52$ & 14,933 & $17,422.92$ & 805.58 & Beta-glucosidase ( $\beta$-glu) \\
\hline 2 & 155.22 & 74.13 & 33.18 & 2083.05 & 1710.45 & 1894.37 & 21.67 & $\beta$-glu \\
\hline 3 & 3.77 & 6.62 & 2.54 & 142.5 & 115.49 & 155.4 & 31.97 & $\beta$-glu \\
\hline 4 & 7.48 & 8.04 & 5.17 & 42.09 & 33.5 & 45.03 & 5.83 & $\beta$-glu \\
\hline 5 & 2.05 & 1.03 & 0 & 4.09 & 6.1 & 7.2 & 5.65 & $\beta$-glu \\
\hline 6 & 3.78 & 2.81 & 0.7 & 11.19 & 9.1 & 9.86 & 4.14 & Caffeoyl shikimate esterase (CSE) \\
\hline 7 & 465.74 & 161.68 & 190.09 & 2399.52 & 1859.24 & 1698.44 & 7.29 & Peroxidase (POX) \\
\hline 8 & 4.54 & 2.66 & 1.43 & 80.63 & 86.14 & 88.92 & 29.63 & Phenylalanine ammonia-lyase (PAL) \\
\hline \multicolumn{9}{|c|}{ Downregulation } \\
\hline 1 & 20.32 & 31.86 & 33.62 & 3.25 & 2.01 & 1.78 & 12.19 & $\beta$-glu \\
\hline 2 & 20.28 & 39.17 & 33.93 & 2.64 & 3.32 & 1.07 & 13.28 & $\beta$-glu \\
\hline 3 & 11.21 & 9.75 & 7.58 & 0.56 & 0.7 & 0.99 & 12.68 & $\beta$-glu \\
\hline 4 & 3.86 & 2.14 & 5.57 & 0.90 & 0.40 & 0.21 & 7.66 & $\beta$-glu \\
\hline 5 & 2.66 & 3.85 & 10.03 & 0.46 & 1.04 & 0.15 & 10.02 & $\beta$-glu \\
\hline 6 & 4.33 & 7.10 & 12.75 & 2.16 & 1.69 & 0.80 & 5.20 & $\beta$-glu \\
\hline 7 & 23.73 & 22.81 & 19.56 & 2.33 & 4.39 & 2.31 & 7.32 & Caffeic acid 3-O-methyltransferase (COMT) \\
\hline 8 & 16.97 & 31.76 & 18.5 & 2.77 & 4.32 & 2.42 & 7.07 & Cinnamyl alcohol dehydrogenase (CAD) \\
\hline 9 & 11.37 & 11.17 & 8.95 & 0.37 & 1.18 & 0.26 & 17.40 & Alcohol dehydrogenase (ADH) \\
\hline 10 & 23.93 & 3.05 & 37.5 & 0.62 & 2.51 & 1.43 & 14.14 & $\mathrm{ADH}$ \\
\hline 11 & 126.14 & 95.94 & 92.17 & 1.37 & 2.07 & 1.55 & 62.98 & POX \\
\hline 12 & 16.26 & 19.69 & 22.67 & 1.72 & 5.12 & 2.42 & 6.33 & POX \\
\hline 13 & 11.92 & 15.52 & 19.01 & 1.54 & 2.01 & 3.48 & 6.61 & POX \\
\hline 14 & 166.23 & 120.17 & 321.94 & 27.64 & 31.88 & 25.61 & 7.15 & Caffeoyl-CoA O-methyltransferase (CCOAOMT) \\
\hline 15 & 39.4 & 40.37 & 44.63 & 2.16 & 1.55 & 2.60 & 19.71 & Acetyl-CoA-benzylalcohol acetyltransferase (BEAT) \\
\hline
\end{tabular}

that are significantly up- and down-regulated. There were $11 \beta$-glu genes showed significant changes, especially the upregulations of three $\beta$-glu genes by 805.58 fold, 21.67-fold, and 31.97-fold (Table 2), suggesting their importance. $\beta$-Glu belongs to the glucohydrolase enzyme family 1 and functions in detoxification, ripening, and defense [56]. The deposition of active $\beta$-glu in the cell wall during fruit ripening and its ability to hydrolase complex glycans could be indicative of a role in degrading cell wall components to trigger fruit soften. The alterations in $\beta$-glu activity and its products of enzymatic hydrolysis are firmly associated with product quality [57]. Under some unfavorable conditions, $\beta$-glu could cleave the glucoside to synthesize glucose and coumaric acid, which is spontaneously cyclized to coumarin [58]. In the 2nd-day noni fruit, the upregulation of coumarin by 1.69-fold (Additional file 1: Table S2) was likely due to the large expressions of $\beta$-glu genes (Fig. 4).

Coumarin is a compound with a simple structural unit and is found in numerous plants, including in noni. It can interact with diverse enzymes and receptors in living organisms [59]. Coumarin has many important properties, including acting as a plant growth regulator, and providing antioxidant, antibacterial, antifungal, analgesic, anti-inflammatory, and antimutagenic properties [60], and it could also be used as biological pesticide [61]. The upregulation of coumarin in noni fruit after harvest on the second day was positive for the disease resistance and storage tolerance.

Our results showed the genes of PAL (phenylalanine ammonia-lyase), COMT (caffeic acid 3-O-methyltransferase), CAD (cinnamyl alcohol dehydrogenase), and POX (peroxidase) were changed a lot in phenylalanine metabolism, for example, $P A L$ upregulated by 29.63 fold and POX upregulated by 7.29 -fold (Table 2), indicating the pathway was disturbed most. The pathway is closely linked to fruit ripening processes [62], and these key enzymes are also associated with lignin synthesis [63]. Therefore, the ripening and softness of noni fruit after harvest might be heavily influenced by phenylalanine metabolism.

Vanillin is one of the secondary metabolites of phenylalanine metabolism, and numerous key enzymes in the pathway possibly act in the catalytic reactions to synthesize vanillin, including PAL [64] and COMT [65]. The significant changes in genes of PAL, COMT, and 
CCoAOMT in the upstream of vanillin suggested they might participate in the biosynthetic pathway of vanillin (Fig. 4). Vanillin, the established active and representative ingredient in noni fruit [66], was upregulated by 1.77 -fold (Additional file 1: Table S2). It possesses an intensely sweet and very tenacious creamy vanillalike odor [67], and could be used as a nutraceutical, antioxidant, antimicrobial and ripening agent [68, 69]. Because of the antioxidant and antimicrobial properties, vanillin could be used as a food preservative [70]. Consequently, the increase of vanillin in postharvest noni fruit helped in the fruit's resistance to bacteria and oxidation and promoted ripening.

Moreover, vanillin is found in a conjugated form as $\beta$-D-glucoside, which could be catalyzed by $\beta$-glu to free vanillin [71]. In the 2nd-day noni fruit, numerous $\beta$-glu genes were identified but not the accumulation of vanillin glucoside, so it was speculated that some $\beta$-glu genes took part in the biological process that dissociated vanillin glucoside. In other words, the accumulation of vanillin was partly due to $\beta$-glu. In addition, it was reported that vanillin could be produced from esters of coniferyl alcohol by lipoxygenase [72], and based on the downregulation of coniferyl alcohol in the metabolome in the $2 \mathrm{~d}$ noni samples relative to the $0 \mathrm{~d}$ samples, coniferyl alcohol might have been consumed to synthesize vanillin. In brief, the upregulation of vanillin in the postharvest noni fruit was owing to three reasons; firstly, the upregulation of PAL genes resulted in a lot of substrate; secondly, beta-glucosidase caused vanillin glucoside to convert to vanillin; thirdly, a part of vanillin might be formed from coniferyl alcohol. Vanillin in noni fruit was significantly upregulated on the second day after harvest and provides the material base for the increase of defense.

Contrary to the increase of coumarin and vanillin, coniferyl alcohol and (-)-epigallocatechin (EGC) decreased (Additional file 1: Table S2). Coniferyl alcohol could be synthesized from coniferyl aldehyde catalyzed by CAD [73] with the downregulation by 2.58 -fold in the $2 \mathrm{~d}$ samples relative to the $0 \mathrm{~d}$ samples (Table 2). The CAD gene was downregulated by 7.07-fold (Table 2), which should be the direct cause of the downregulation of coniferyl alcohol (Fig. 4). The other cause could be that coniferyl alcohol was transformed into vanillin, as mentioned above. Considering that coniferyl alcohol is one

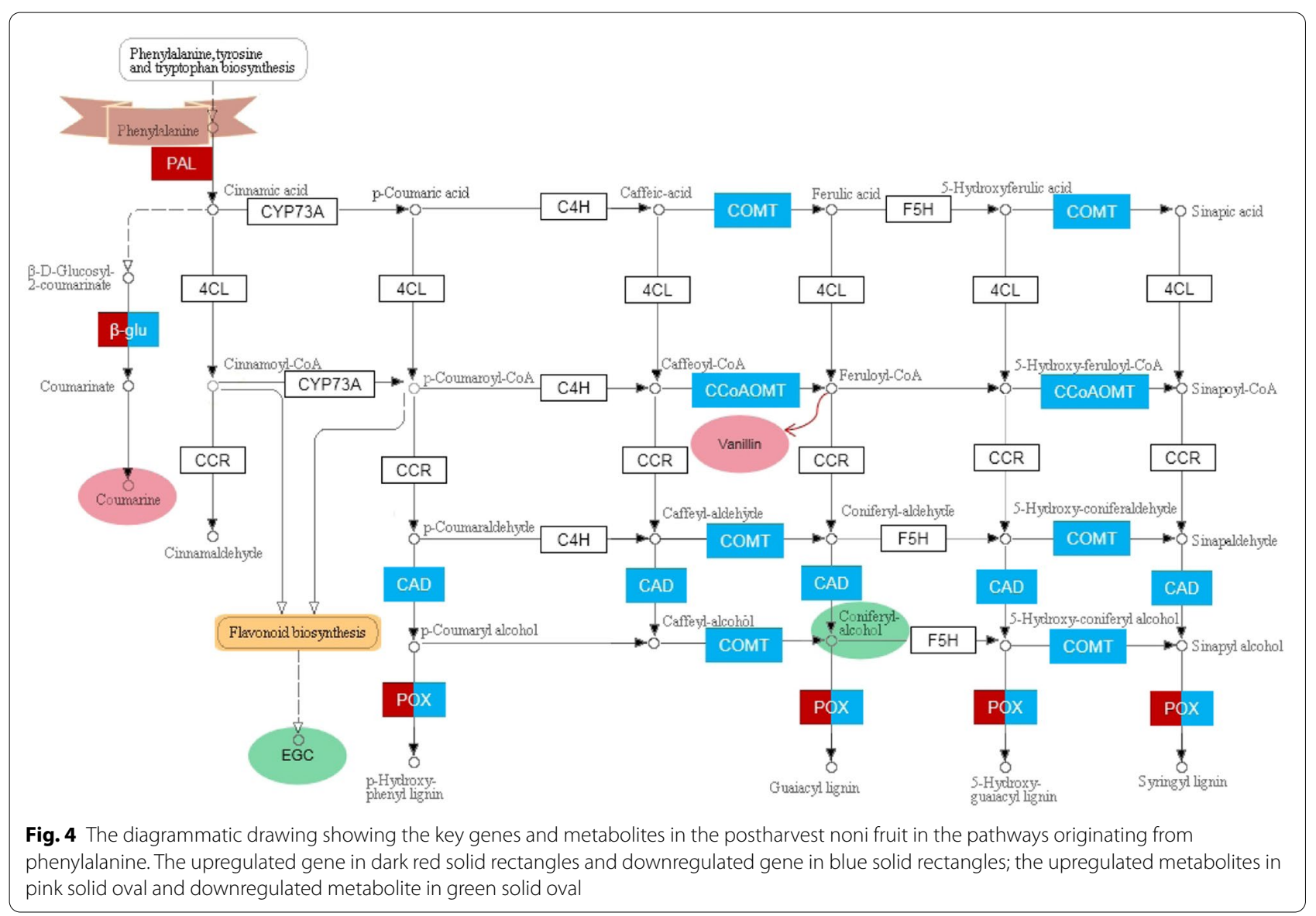


of the lignin precursors [74], and the coniferyl alcohol was positively correlated with hardness in fruit [63], the downregulation of coniferyl alcohol may be one of the causes for noni fruit softening after harvest.

In flavonoid biosynthesis, only one metabolite and one gene were significantly altered, downregulating by 4.30-fold (Additional file 1: Table S2) in EGC and by 19.71-fold (Table 2) in the acetyl-CoA-benzyl alcohol acetyltransferase (BEAT) gene. BEAT could catalyze p-coumaroyl-CoA in flavonoid biosynthesis [75]. Flavonoid biosynthesis starts with general phenylpropanoid metabolism and the precursor of EGC is p-coumaroylCoA [76]. The downregulation of the BEAT gene might be because p-coumaroyl-CoA was consumed and synthesized into vanillin since p-coumaroyl-CoA is also a precursor substrate for vanillin. In other words, when the substrate was competed for the pathway to vanillin won over the pathway to BEAT (Fig. 4). As a secondary metabolite synthesized downstream in flavonoid biosynthesis, EGC must be downregulated due to its inactive enzymatic reaction upstream. It was reported that EGC has stronger antioxidant and antibacterial effects [77]; therefore, its decrease might result in the decrease of antioxidant and antibacterial effects, which would negatively impact the fruit's resistance to pathogens. However, from the other angle, the decline of resistance might be favorable for energy retention.

In summary, coumarin and vanillin showed upregulation, which is effective at increasing resistance but consumed energy, while coniferyl alcohol and EGC showed downregulation, which may be an effort to save energy.

\section{Upregulations of isoprene and 2,3-epoxymenaquinone and the downregulation of IPA in terpene-related pathways}

The terpenoid backbone biosynthesis as well as the ubiquinone and other terpenoid-quinone biosynthesis pathways were affected the 2nd-day noni fruit. In these two terpene-related pathways, two genes encoding isoprenyl cysteine alpha-carbonyl methylesterase (ICME) were upregulated by 17.76 -fold and 10.59-fold and two 4-hydroxyphenylpyruvate dioxygenase (HPPD) were upregulated by 3.01-fold and 6.03-fold (Additional file 1: Table S4). Additionally, four genes were downregulated: geranylgeranyl pyrophosphate synthase (GGPPS) was downregulated by 5.15 -fold, tyrosine aminotransferase (TAT) by 5.62 -fold, 4-hydroxybenzoate geranyltransferase (4-PHB) by 5.44-fold, and 1,4-dihydroxy-2-naphthoyl-CoA synthase (DHNA-CoA) by 5.54-fold (Additional file 1: Table S4). ICME may be involved in abscisic acid (ABA) signaling as a positive regulator [78, 79]. The upregulated ICME genes might, therefore, cause the ABA signaling pathway in the postharvest noni fruit.
HPPD can catalyze the conversion of 4-hydroxyphenylpyruvate to homogentisate [80], and the homogentisate might be one of the substrates that go into terpenoid backbone biosynthesis. Given that there was no upregulated gene found in the upstream of isoprene in the terpenoid backbone biosynthesis, we speculate that the upregulated expression of the HPPD gene would produce homogentisate, which would start the terpenoid backbone biosynthesis and further accumulate isoprene (Fig. 5).

Isoprene was upregulated by 1.68 -fold in the noni fruit on the second day after harvesting (Additional file 1: Table S2). It is a volatile organic compound with a petroleum-like odor. Its biosynthesis occurs through the methylerythritol 4-phosphate (MEP) pathway in terpenoid backbone biosynthesis, and only parts of plants could make isoprene through MEP pathway [81]. Nearly all the carbon producing isoprene comes directly from photosynthetic intermediates [82], and the emission of isoprene is a character of having a high metabolism in higher plants [83]. Its emission hardly reaches $2-5 \%$ of the carbon fixed by photosynthesis in healthy plants, but it often increases under stressful conditions [84]. Therefore, the upregulation of isoprene may indicate that the noni fruit on the second day of harvest was in vigorous metabolism and was consuming energy in abundance. Furthermore, isoprene is very active due to its diene with conjugated double bonds; consequently, the increase of isoprene could increase the fruit's resistance to abiotic and biotic stresses $[85,86]$. In summary, the upregulation of isoprene is beneficial to post harvested noni fruit responding to stress conditions; however, it also accelerates the consumption of photosynthetic products, which might be a double-edged sword.

2,3-Epoxymenaquinone was upregulated by 3.96 -fold (Additional file 1: Table S2). It, is also named vitamin $\mathrm{K} 2$ 2,3-epoxide, is a vitamin $\mathrm{K}$ metabolite occurring in the ubiquinone and other terpenoid-quinone biosynthesis. In the pathway, vitamin K2 (menaquinone) is in the upstream of 2,3-epoxymenaquinone. The upregulation of 2,3-epoxymenaquinone meant that vitamin $\mathrm{K} 2$ was consumed. There are two main forms of vitamin $\mathrm{K}$, vitamin $\mathrm{K} 1$ found in plant foods and vitamin $\mathrm{K} 2$ found in animal and fermented foods [87]. Therefore, the upregulation of 2,3-epoxymenaquinone might suggest that the harvested noni fruit was beginning to ferment, which also caused the fruit flesh water spot appearance and even to be soft.

Zeatin biosynthesis could be regarded as a branch of terpenes, and there was one downregulated metabolite, isopentenyl adenosine (iPA), and one upregulated gene, zeatin O-glucosyltransferase (ZOG), in the pathway (Fig. 5). The multiple of downregulated iPA was the largest among the metabolites mentioned in this study, 


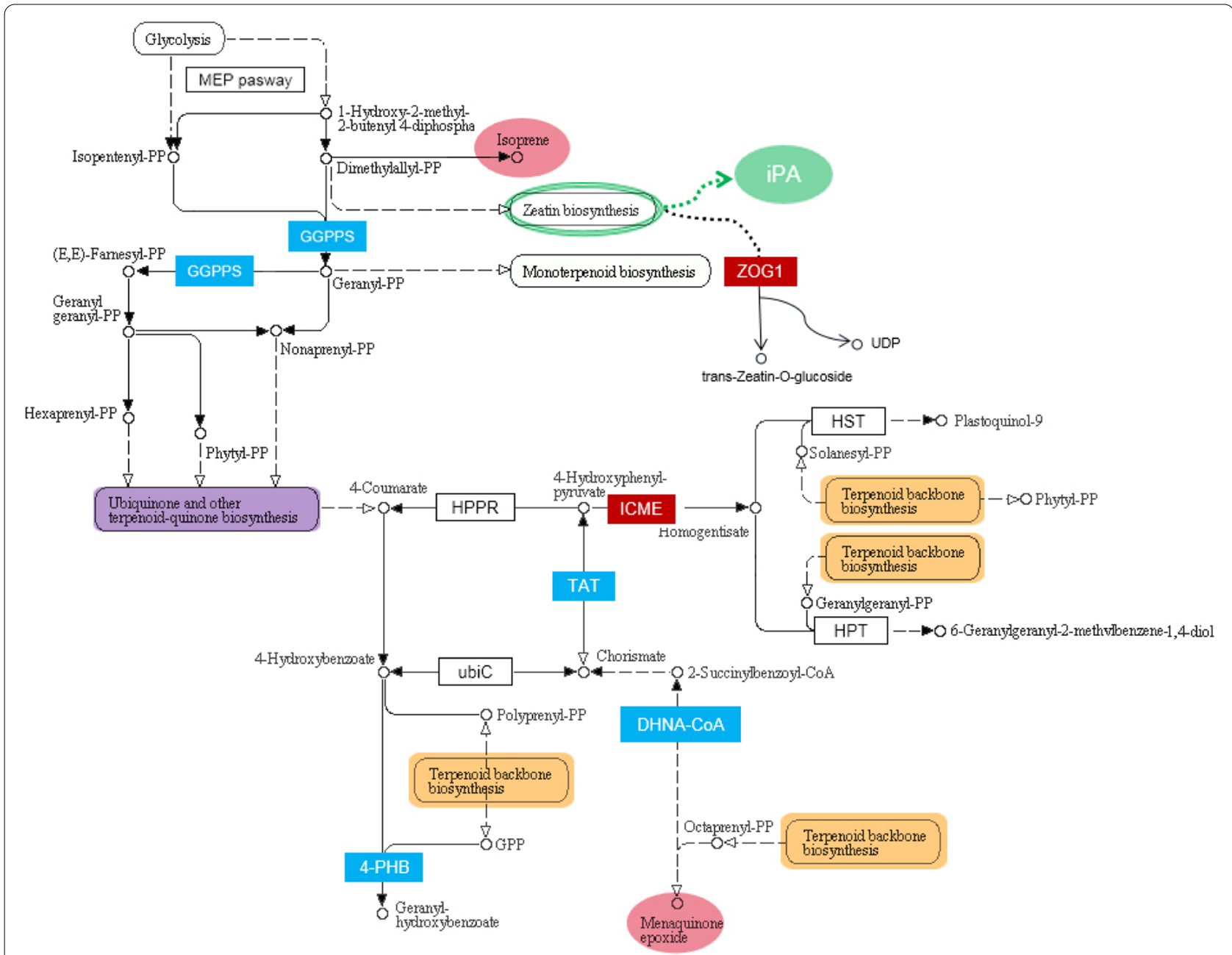

Fig. 5 The diagrammatic drawing showing the key genes and metabolites in the postharvest noni fruit in the terpene-related pathways

reaching 125.33 times (Additional file 1: Table S2). IPA, a member of the cytokinin family, is a product of the MEP. And isoprene is also located in MEP. Dimethylallylpp is the common precursor of iPA and isoprene, which might lead to the downregulation of iPA due to substrate competition. Not only that, but iPA is in the upstream of ZOG, and ZOG was upregulated, meaning it needed to consume iPA; therefore, iPA must be further downregulated. ZOG can catalyze zeatin to O-glucosylzeatin. The formation of O-glucosylzeatin is reversible by betaglucosidase [88], and several beta-glucosidase genes were massively upregulated as mentioned in phenylpropanoid biosynthesis. This reversibility implied the activity of cytokinin-related pathways. In summary, the upregulation of isoprene and the ZOG gene together resulted in the downregulation of iPA by a large amount.

Cytokinins inhibit fruit ripening and act in the resistance [89]. As the fruit ripens, the amount of cytokinin increases [42]. In reaction to the postharvest noni fruit, although the iPA decreased, the downstream metabolite trans-zeatin-O-glucoside synthesized by ZOG might increase. In addition, the upregulated ICME genes in terpenoid backbone biosynthesis were positive regulators of ABA signaling, suggesting the possibility of accumulation of ABA. All of these results indicated that cytokinins were involved in the post-ripening process of noni fruit. Although cytokinins can reduce the post-ripening process, not all cytokinins work at the same time, which could consume more energy and negatively affect fruit quality.

\section{Glycerol as substrate could be oxidized to DHA in glycerolipid metabolism}

Glycerolipid metabolism was disturbed in postharvest noni fruit. The metabolite dihydroxyacetone (DHA) was upregulated by 4.51-fold (Additional file 1: Table S2), 


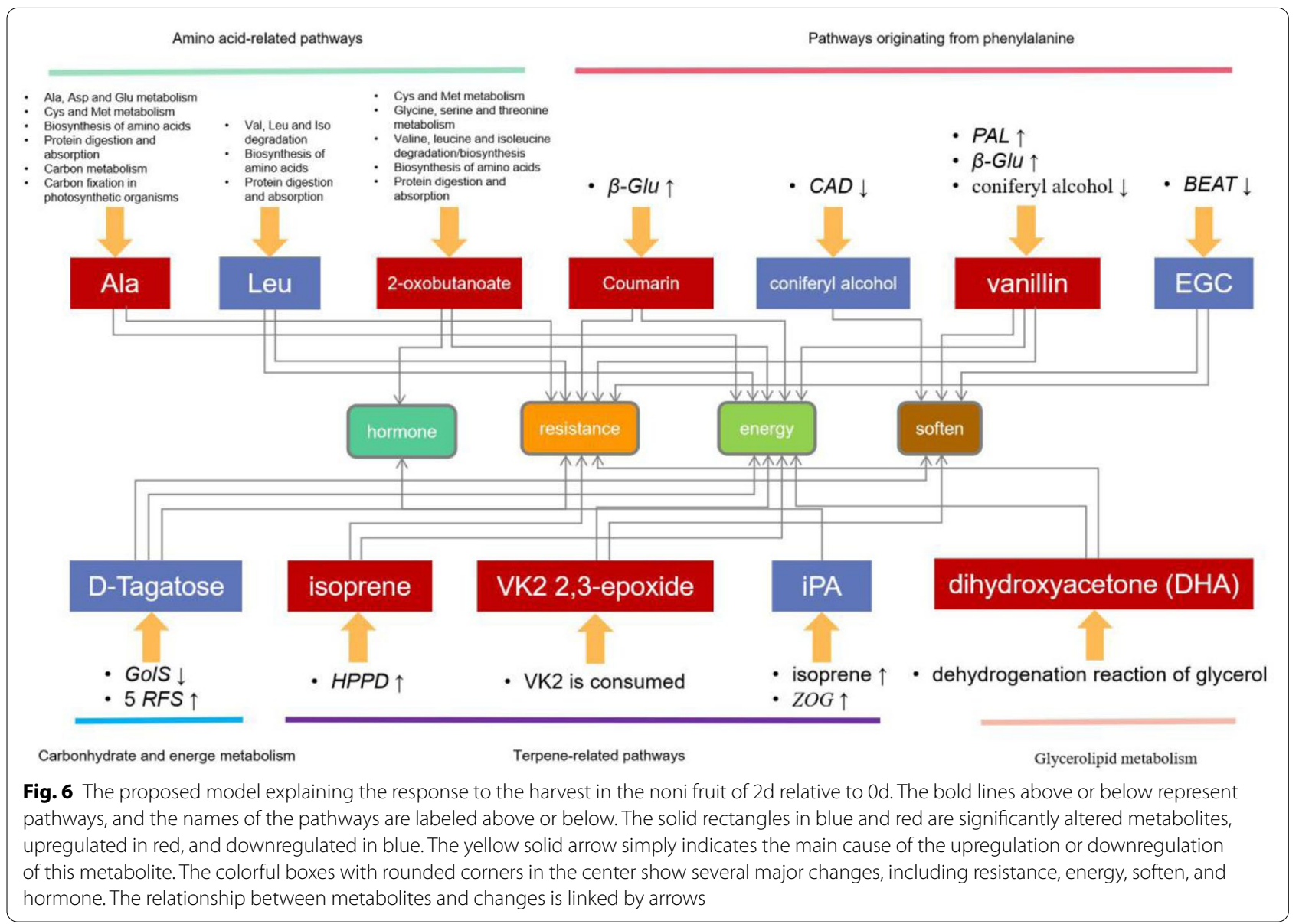

while the gene glycerol-3-phosphate 2-O-acyltransferase 4 (GPAT4) was upregulated by 3.60 -fold and 1-acyl-snglycerol-3-phosphate acyltransferase 5 (AGPAT5) was downregulated by 5.54-fold (Additional file 1: Table S5). DHA, also known as glycerone, is the simplest ketone form of ketoses and is an important intermediate in carbohydrate metabolism in higher plants during glycolysis [90]. Therefore, the upregulation of DHA is obviously closely related to energy consumption.

Glycerol as a substrate can be biosynthesized to DHA and also be catalyzed by GPAT4 to 1-acyl-sn-glycerol 3-phosphate (Additional file 1: Fig. S1). GPAT is the ratelimiting enzyme in glycerolipid synthesis and plays a pivotal role [91], and 1-acyl-sn-glycerol 3-phosphate can be further catalyzed by AGPAT5, which was reduced in the 2nd-day noni fruit, meaning that 1-acyl-sn-glycerol 3-phosphate might accumulate. Glycerolipid metabolism may participate in stress response signaling in response to the phospholipid precursor [92], so it might increase the resistance of postharvest noni fruit more or less by energy expenditure.

\section{Conclusions}

A hypothesis model was proposed by the conjoint analysis of transcriptomic and metabolomic profiles in noni fruit on the second day vs. the initial day of harvesting (Fig. 6). This model indicated that the primary metabolic pathways, including amino acid-related pathways as well as carbohydrate and energy metabolism, were disturbed. The affected secondary metabolic pathways included pathways originating from phenylalanine, terpene-related pathways, zeatin biosynthesis, as well as glycerolipid metabolism. Numerous resistance metabolites, including Ala, coumarin, vanillin, and isoprene, and resistance genes, including $\beta$-glu, $P A L, P O X, G 6 P D H, S 6 P D H$, and $A K R$, were upregulated, which implied the increase of resistance in the postharvest noni fruit. As a result, a great deal of energy was consumed. Not all resistant metabolites were upregulated, such as EGC and D-tagatose, which may be trivial compared with the number that were upregulated, but could indicate a struggle between consumption and saving energy. In addition, $P G K$, 
PPDK, PKC, PKP, and $H X K$ were all downregulated in glycolysis, further limiting energy. The lack of energy led noni fruit to water spot appearance, a prelude to softening, and the downregulation of coniferyl alcohol and D-tagatose directly led to softening. Upregulation of 2,3-epoxymenaquinone suggested the initiation of fermentation, which would also lead to softening. The metabolites and genes related to the resistance and energy interacted and restricted each other to keep noni fruit seemingly hard within two days after harvest, but actually the softening was already unstoppable. Moreover, the cytokinin and ethylene pathways were also subtly altering in preparation for the following acceleration of softening. Our results lay a foundation for the clarification of noni's post-ripening mechanism and could scientifically guide the optimal storage time of noni fruit.

\section{Supplementary Information}

The online version contains supplementary material available at https://doi. org/10.1186/s40538-020-00207-2.

Additional file 1: Fig. S1. The diagrammatic drawing showing the key genes and the upregulation of glycerone (DHA) in the postharvest noni fruit in glycerolipid metabolism. The upregulated genes in dark red solid rectangles and downregulated genes in blue solid rectangles; the upregulated metabolite in red solid oval. Table $\mathbf{S 1}$ The differential metabolites in all three comparisons. Table S2. Metabolites located in the pathways significantly altered at both metabolic and transcriptional levels. Table S3. DEGs in amino acid-related pathways. Table S4. DEGs in terpene-related pathways. Table S5. DEGs in glycerolipid metabolism.

\section{Acknowledgements}

Not applicable.

\section{Authors' contributions}

TW designed the experiments and completed the manuscript. DH conducted the data analysis and prepared the figures. QW prepared the tables and wrote parts of the manuscript. All the authors have read and approved the final manuscript.

\section{Funding}

This work was supported by the Extension Project of State Administration of Forestry and Grassland, China (No. [2019]27) and the fund of China Scholarship Council (201908535030).

\section{Availability of data and materials}

The RNA-seq data are available in the database of NCBI with an accession number of PRJNA503490.

\section{Ethics approval and consent to participate \\ Not applicable.}

\section{Consent for publication}

Not applicable.

\section{Competing interests}

The authors declare that they have no competing interests.

Received: 12 October 2020 Accepted: 30 December 2020 Published online: 02 February 2021

\section{References}

1. McClatchey W. From Polynesian healers to health food stores: changing perspectives of Morinda citrifolia (Rubiaceae). Integr Cancer Ther. 2002;1(2):110-20.

2. Pandy V, Narasingam M, Vijeepallam K, Mohan S, Mani V, Mohamed Z. The ethyl acetate fraction of a methanolic extract of unripe noni (Morinda citrifolia Linn.) fruit exhibits a biphasic effect on the dopaminergic system in mice. Exp Anim. 2017;66(3):283-91.

3. Furusawa E, Hirazumi A, Story S, Jensen J. Antitumour potential of a polysaccharide-rich substance from the fruit juice of Morinda citrifolia (Noni) on sarcoma 180 ascites tumour in mice. Phytother Res. 2003;17(10):1158-64.

4. Su BN, Pawlus AD, Jung HA, Keller WJ, McLaughlin JL, Kinghorn AD. Chemical constituents of the fruits of Morinda citrifolia (Noni) and their antioxidant activity. J Nat Prod. 2005;68(4):592-5.

5. Siddiqui BS, Sattar FA, Ahmad F, Begum S. Isolation and structural elucidation of chemical constituents from the fruits of Morinda citrifolia Linn. Arch Pharmacal Res. 2007:30(8):919-23.

6. West BJ, Deng S, Isami F, Uwaya A, Jensen CJ. The potential health benefits of Noni juice: a review of human intervention studies. Foods. 2018;7(4):58.

7. Westendorf J, Mettlich C. The benefits of noni juice: an epidemiological evaluation in Europe. J Med Plants Res. 2009;1:64-79.

8. Brown AC. Anticancer activity of Morinda citrifolia (Noni) fruit: a review. Phytother Res. 2012;26(10):1427-40.

9. Nelson S. Noni seed handling and seedling production. Fruits and Nuts. 2005;10:8-11.

10. Motshakeri M, Ghazali HM. Nutritional, phytochemical and commercial quality of noni fruit: a multi-beneficial gift from nature. Trends Food Sci. 2015:45(1):118-29.

11. Cárdenas-Coronel WG, Carrillo-López A, de la Rocha RV, Labavitch JM, Báez-Sañudo MA, Heredia JB, Zazueta-Morales JJ, Vega-García MO, Sañudo-Barajas JA. Biochemistry and cell wall changes associated with noni (Morinda citrifolia L.) fruit ripening. J Agric Food Chem. 2016;64(1):302-9.

12. Chen YH, Hung YC, Chen MY, Lin HT. Effects of acidic electrolyzed oxidizing water on retarding cell wall degradation and delaying softening of blueberries during postharvest storage. LWT-Food Sci Technol. 2017;84:650-7.

13. Wang DD, Yeats TH, Uluisik S, Rose JKC, Seymour GB. Fruit softening: revisiting the role of pectin. Trends Plant Sci. 2018;23(4):302-10.

14. Pétriacq P, López A, Luna E. Fruit decay to diseases: can induced resistance and priming help? Plants. 2018;7(4):77.

15. Thaler JS, Fidantsef AL, Duffey SS, Bostock RM. Trade-Offs in plant defense against pathogens and herbivores: a field demonstration of chemical elicitors of induced resistance. J Chem Ecol. 1999;25(7):1597-609.

16. Wu T, Li M, Lan ZQ. Reveal the variation patterns of chemical composition in the fruit of Morinda citrifolia (noni) during postharvest storage through metabolomic characterization. Tropical Plant Biology. 2019;12(2):85-97.

17. Luo B, Groenke K, Takors R, Wandrey C, Oldiges M. Simultaneous determination of multiple intracellular metabolites in glycolysis, pentose phosphate pathway and tricarboxylic acid cycle by liquid chromatography-mass spectrometry. J Chromatogr A. 2007;1 147(2):153-64.

18. Plaxton WC. The organization and regulation of plant glycolysis. Annu Rev Plant Biol. 1996:47(47):185-214.

19. Rosa-Téllez S, Anoman AD, Flores-Tornero M, Toujani W, Alseek S, Fernie $A R$, et al. Phosphoglycerate kinases are co-regulated to adjust metabolism and to optimize growth. Plant Physiol. 2018;176(2):1182-98.

20. Oliver SN, Lunn JE, Urbanczyk-Wochniak E, Lytovchenko A, van Dongen $J T$, Faix B, et al. Decreased expression of cytosolic pyruvate kinase in potato tubers leads to a decline in pyruvate resulting in an in vivo repression of the alternative oxidase. Plant Physiol. 2008;148(3):1640-54.

21. Kim KJ, Park CJ, Ham BK, Choi SB, Lee BJ, Paek KH. Induction of a cytosolic pyruvate kinase 1 gene during the resistance response to Tobacco mosaic virus in Capsicum annuum. Plant Cell Rep. 2006;25(4):359-64.

22. Qin $Q P$, Kaas $Q$, Zhang $L L$, Xu K, Li NY, Zheng WW, et al. Isolation and characterization of a cytosolic pyruvate kinase cDNA from loquat (Eriobotrya japonica Lindl). Plant Mol Biol Rep. 2013;31(1):109-19. 
23. Aguilera-Alvarado GP, Sánchez-Nieto S. Plant hexokinases are multifaceted proteins. Plant Cell Physiol. 2017;58(7):1151-60.

24. Liang LY, Liu RM, Ma JF, Chen KQ, Jiang M, Wei P. Increased production of succinic acid in Escherichia coli by overexpression of malate dehydrogenase. Biotechnol Lett. 2011;33(12):2439-44.

25. Silva FLB, Vieira LGE, Ribas AF, Moro AL, Neris DM, Pacheco AC. Proline accumulation induces the production of total phenolics in transgenic tobacco plants under water deficit without increasing the G6PDH activity. Theo Exp Plant Phys. 2018;30(3):251-60.

26. Jing $Y$, Lang SR, Wang DM, Xue $H$, Wang XF. Functional characterization of galactinol synthase and raffinose synthase in desiccation tolerance acquisition in developing Arabidopsis seeds. J Plant Physiol. 2018;230:109-21.

27. Peterbauer T, Mach L, Mucha J, Richter A. Functional expression of a cDNA encoding pea (Pisum sativum L.) raffinose synthase, partial purification of the enzyme from maturing seeds, and steady-state kinetic analysis of raffinose synthesis. Planta. 2002;215(5):839-84.

28. Li T, Zhang YM, Liu Y, Li XD, Hao GL, Han QH, et al. Raffinose synthase enhances drought tolerance through raffinose synthesis or galactinol hydrolysis in maize and Arabidopsis plants. J Biol Chem. 2020:295(23):8064-77.

29. Kanayama Y, Mori H, Imaseki H, Yamaki S. Nucleotidic sequence of a cDNA encoding NADP-sorbitol 6-phosphate dehydrogenase from apple. Plant Physiol. 1992;100(3):1607-8.

30. Rojas B, Wurman J, Zamudio MS, Donoso A, Cabedo P, et al. AtA6PR1 and AtA6PR2 encode putative aldose 6-phosphate reductases that are cytosolically localized and respond differentially to cold and salt stress in Arabidopsis thaliana. J Plant Biochem Biot. 2019;28(1):114-9.

31. Yang YT, Fu ZW, Su YC, Zhang X, Li GY, Guo JL, et al. A cytosolic glucose-6-phosphate dehydrogenase gene, ScG6PDH, plays a positive role in response to various abiotic stresses in sugarcane. Sci Rep-Uk. 2014:4(1):243-56.

32. Ruiz FX, Porté S, Parés $X$, Farrés J. Biological role of aldo-keto reductases in retinoic acid biosynthesis and signaling. Front Pharmacol. 2012;3:58.

33. Jiang YM, Jiang YL, Qu HX, Duan XW, Luo YB, Jiang WB. Energy aspects in ripening and senescence of harvested horticultural crops. Stewart Postharvest Review. 2007;2:1-5.

34. Machingura M, Salomon E, Jez JM, Ebbs SD. The $\beta$-cyanoalanine synthase pathway: beyond cyanide detoxification. Plant Cell Environ. 2016;39(10):2329-41.

35. Taji T, Ohsumi C, luchi S, Seki M, Kasuga M, Kobayashi M, et al. Important roles of drought-and cold-inducible genes for galactinol synthase in stress tolerance in Arabidopsis thaliana. Plant J. 2002;29(4):417-26.

36. Li L, Wang X, Zhang X, Guo M, Liu T. Unraveling the target genes of RIN transcription factor during tomato fruit ripening and softening. J Sci Food Agric. 2017;97(3):991-1000.

37. Ross GS, Redgwell RJ, MacRae EA. Kiwifruit $\beta$-galactosidase: isolation and activity against specific fruit cell-wall polysaccharides. Planta. 1993;189(4):499-506.

38. Imsabai W, Ketsa S, van Doorn WG. Effect of temperature on softening and the activities of polygalacturonase and pectinesterase indurian fruit. Postharvest Biol Technol. 2002;26(3):347-51.

39. Ban QY, Han Y, He YH, Jin MJ, Han SK, Suo JT, et al. Functional characterization of persimmon $\beta$-galactosidase gene DKGAL1 in tomato reveals cell wall modification related to fruit ripening and radicle elongation. Plant Sci. 2018:274:109-20.

40. Oh DK. Tagatose: properties, applications, and biotechnological processes. Appl Microbiol Biotechnol. 2007;76(1):1-8.

41. Roy S, Chikkerur J, Roy SC, Dhali A, Kolte AP, Sridhar M, et al. Tagatose as a potential nutraceutical: Production, properties, biological roles, and applications. J Food Sci. 2018;83(11):2699-709.

42. Gojło E, Pupel P, Lahuta LB, Podliński P, Kucewiczb M, Góreckia RJ. The acquisition of desiccation tolerance in developing Vicia hirsuta seeds coincides with an increase in galactinol synthase expression and soluble a-d-galactosides. J Plant Physiol. 2015:184:37-48.

43. Levin GV, Lu YM. D-tagatose as an anti-biofilm agent. US Patent:US7189351B2. 2007.

44. Araújo WL, Nunes-Nesi A, Osorio S, Usadel B, Fuentes D, Nagy R, et al. Antisense inhibition of the iron-sulphur subunit of succinate dehydrogenase enhances photosynthesis and growth in tomato via an organic acid-mediated effect on stomatal aperture. Plant Cell. 2011;23(2):600-27.

45. Giovannoni J, Nguyen C, Ampofo B, Zhong SL, Fei ZJ. The epigenome and transcriptional dynamics of fruit ripening. Annu Rev Plant Biol. 2017;68:61-84.

46. Flaherty EJ, Lum GB, DeEll JR, Subedi S, Shelp BJ, Bozzo GG. Metabolic alterations in postharvest pear fruit as influenced by 1-methylcyclopropene and controlled atmosphere storage. J Agr Food Chem. 2018;66(49):12989-99.

47. Narsai R, Rocha M, Geigenberger P, Whelan J, Van Dongen JT. Comparative analysis between plant species of transcriptional and metabolic responses to hypoxia. New Phytol. 2011;190(2):472-87.

48. Rowan DD, Lane HP, Allen JM, Fielder S, Hunt MB. Biosynthesis of 2-methylbutyl, 2-methyl-2-butenyl, and 2-methylbutanoate esters in red delicious and granny smith apples using deuterium-labeled substrates. J Agric Food Chem. 1996:44(10):3276-85.

49. Wyllie SG, Fellman JK. Formation of volatile branched chain esters in bananas (Musa sapientum L ). J Agric Food Chem. 2000;48(8):3493-6.

50. Perez AG, Olias R, Luaces P, Sanz C. Biosynthesis of strawberry aroma compounds through amino acid metabolism. J Agric Food Chem. 2002;50(14):4037-42

51. Jin JY, Zhao MY, Zhang N, Jing TT, Liu HT, Song CK. Stable isotope signatures versus gas chromatography-ion mobility spectrometry to determine the geographical origin of Fujian Oolong tea (Camellia sinensis) samples. Eur Food Res Technol. 2020;246(5):955-64

52. Hall CJ, Mackie ERR, Gendal AR, Perugini MA, da Soares Costa TP. Amino acid biosynthesis as a target for herbicide development. Pest Manag Sci. 2020. https://doi.org/10.1002/ps.5943.

53. Teng YW, Mehedint MG, Garrow TA, Zeisel SH. Deletion of betaine-homocysteine S-methyltransferase in mice perturbs choline and 1-carbon metabolism, resulting in fatty liver and hepatocellular carcinomas. J Biol Chem. 2011;286(42):36258-67.

54. Van de Poel B, Bulens I, Oppermann Y, Hertog MLATM, Nicolai BM, Sauter $M$, et al. S-adenosyl-I-methionine usage during climacteric ripening of tomato in relation to ethylene and polyamine biosynthesis and transmethylation capacity. J Biol Chem. 2013;148(2):176-88.

55. Pholoma SB. Is Ethylene the ripening hormone? Int J Agric Biol. 2020;42:1-7.

56. Mazzuca S, Spadafora A, Innocenti AM. Cell and tissue localization of $\beta$-glucosidase during the ripening of olive fruit (Olea europaea) by in situ activity assay. Plant Sci. 2006;171(6):726-33.

57. Morello JR, Moltiva MJ, Tovar MJ, Romero MP. Changes in commercial virgin olive oil (cv Arbequina) during storage with special emphasis on phenolic fraction. Food Chem. 2004:85(3):357-64.

58. Verdoucq L, Morinière J, Bevan DR, Esen A, Vasella A, Henrissat B, et al. Structural determinants of substrate specificity in family $1 \beta$-Glucosidases novel insights from the crystal structure of sorghum dhurrinase-1, a plant $\beta$-Glucosidase with strict specificity, in complex with its natural substrate. J Biol Chem. 2004;279(30):31796-803.

59. Annunziata F, Pinna C, Dallavalle S, Tamborini L, Pinto A. An overview of coumarin as a versatile and readily accessible scaffold with broad-ranging biological activities. Int J Mol Sci. 2020;21(13):4618.

60. Bogdal D. Coumarins: fast synthesis by Knoevenagel condensation under microwave irradiation. J Chem Res. 1998;8:468-9.

61. Vekariya $\mathrm{RH}$, Patel HD. Recent advances in the synthesis of coumarin derivatives via knoevenagel condensation: a review. Synthetic Commun. 2014:44(19):2756-88

62. Singh R, Rastogi S, Dwivedi UN. Phenylpropanoid metabolism in ripening fruits. Compr Rev Food Sci Food Saf. 2010;9(4):398-416.

63. Shan LL, Li X, Wang P, Cai C, Zhang B, Sun CD, et al. Characterization of cDNAs associated with lignification and their expression profiles in loquat fruit with different lignin accumulation. Planta. 2008;227(6):1243-54.

64. Fritz RR, Hodgins DS, Abell CW. Phenylalanine ammonia-lyase. Induction and purification from yeast and clearance in mammals. J Biol Chem. 1976;251(15):4646-50.

65. Lam KC, Ibrahim RK, Behdad B, Dayanandan S. Structure, function, and evolution of plant O-methyltransferases. Genome. 2007:50(11):1001-13. 
66. Dussossoy E, Brat P, Bony E, Boudard F, Poucheret P, Mertz C, et al. Characterization, anti-oxidative and anti-inflammatory effects of Costa Rican noni juice (Morinda citrifolia L ). J Ethnopharmacol. 2011;133(1):108-15.

67. Fitzgerald DJ, Stratford M, Gassson MJ, Uecckert J, Bos A, Narbad A. Mode of antimicrobial action of vanillin against Escherihia coli, Lactobacillus plantarum and Listeria innnocua. J Appl Microbiol. 2004;97(1):104-13.

68. Fitzgerald DJ, Stratford M, Gassson MJ, Narbad A. Structure-function analysis of the vanillin molecule and its antifungal properties. J Agric Food Chem. 2005;53(5):1769-75.

69. Banerjee G, Chattopadhyay P. Vanillin biotechnology: the perspectives and future. J Sci Food Agric. 2019;99(2):499-506.

70. Walton NJ, Mayer MJ, Narbad A. Vanillin. Phytochemistry. 2003:63(5):505-15.

71. Kundu A. Vanillin biosynthetic pathways in plants. Planta. 2017;245(6):1069-78.

72. Markus PH, Peters ALJ, Roos R. Process for the preparation of phenylaldehydes. United States patent US 5,358,861. 1994

73. Boerjan W, Ralph J, Baucher M. Lignin biosynthesis. Annu Rev Plant Biol. 2003;54(1):519-46.

74. Goujon T, Sibout R, Eudes A, Mackay J, Jouanina L. Genes involved in the biosynthesis of lignin precursors in Arabidopsis thaliana. Plant Physiol Biochem. 2003;41(8):677-87.

75. Suzuki H, Sawada S, Watanabe K, Nagae S, Yamaguchi M, Nakayama T, et al. Identification and characterization of a novel anthocyanin malonyltransferase from scarlet sage (Salvia splendens) flowers: an enzyme that is phylogenetically separated from other anthocyanin acyltransferases. Plant J. 2010;38(6):994-1003

76. Winkel-Shirley B. Flavonoid biosynthesis: a colorful model for genetics, biochemistry, cell biology, and biotechnology. Plant Physiol. 2001;126(2):485-93.

77. Sourabh A, Kanwar SS, Sud RG, Ghabrull A, Sharma OP. Influence of phenolic compounds of Kangra tea [Camellia sinensis ( $L$ ) O Kuntze] on bacterial pathogens and indigenous bacterial probiotics of Western Himalayas. Braz J Microbiol. 2013;44(3):709-15.

78. Huizinga DH, Omosegbon O, Omery B, Crowell DN. Isoprenylcysteine methylation and demethylation regulate abscisic acid signaling in Arabidopsis. Plant Cell. 2008;20(10):2714-28.

79. Lan P, Li WF, Wang HZ, Ma WJ. Characterization, sub-cellular localization and expression profiling of the isoprenyl cysteine methylesterase gene family in Arabidopsis thaliana. BMC Plant Biol. 2010;10:212.

80. Moran GR. 4-Hydroxyphenylpyruvate dioxygenase. Arch Biochem Biophys. 2005:433:117-28.
81. Sharkey TD, Wiberley AE, Donohue AR. Isoprene emission from plants: why and how. Ann Bot. 2008;101:5-18.

82. Delwiche CF, Sharkey TD. Rapid appearance of ${ }^{13} \mathrm{C}$ in biogenic isoprene when ${ }^{13} \mathrm{CO}_{2}$ is fed into intact leaves. Plant Cell Environ. 1993;16(5):587-91.

83. Loreto F, Fineschi S. Reconciling functions and evolution of isoprene emission in higher plants. New Phytol. 2015;206(2):578-82.

84. Brilli F, Barta C, Fortunati A, Lerdau M, Loreto F, Centritto M. Response of isoprene emission and carbon metabolism to drought in white poplar (Populus alba) saplings. New Phytol. 2007;175(2):244-54.

85. Loivamäki M, Mumm R, Dicke M, Schnitzler J-P. Isoprene interferes with the attraction of bodyguards by herbaceous plants. P Natl Acad Sci USA. 2008;105(45):17430-5.

86. Vickers CE, Gershenzon J, Lerdau MT, Loreto F. A unified mechanism of action for volatile isoprenoids in plant abiotic stress. Nat Chem Biol. 2009;5(5):283-91.

87. Shearer MJ. Vitamin K. Lancet. 1995:345(8944):229-34.

88. Mok MC, Martin RC, Mok DWS. Cytokinins: biosynthesis metabolism and perception. Vitro Cell Dev-PI. 2000;36(2):102-7.

89. Fahima A, Levinkron S, Maytal Y, Hugger A, Lax I, Huang XM, et al. Cytokinin treatment modifies litchi fruit pericarp anatomy leading to reduced susceptibility to post-harvest pericarp browning. Plant Sci. 2019;283:41-50.

90. Ciriminna R, Fidalgo A, Ilharco LM, Pagliaro M. Dihydroxyacetone: an updated insight into an important bioproduct. Chemistry Open. 2018;7(3):233-6.

91. Henry SA, Gaspar ML, Jesch SA. The response to inositol: regulation of glycerolipid metabolism and stress response signaling in yeast. Chem Phys Lipids. 2014;180:23-43.

92. Takeuchi K, Reue K. Biochemistry, physiology, and genetics of GPAT, AGPAT, and lipin enzymes in triglyceride synthesis. Am J Physiol. 2009;296(6):1195-209.

\section{Publisher's Note}

Springer Nature remains neutral with regard to jurisdictional claims in published maps and institutional affiliations.

\section{Submit your manuscript to a SpringerOpen ${ }^{\circ}$ journal and benefit from:}

- Convenient online submission

- Rigorous peer review

- Open access: articles freely available online

- High visibility within the field

- Retaining the copyright to your article

Submit your next manuscript at springeropen.com 